\title{
Brain to Belly: Abdominal Variants of Migraine and Functional Abdominal Pain Disorders Associated With Migraine
}

\author{
Léa Lenglart, ${ }^{1}$ Caroline Caula, ${ }^{1}$ Thomas Moulding, ${ }^{2}$ Annabel Lyles, ${ }^{3}$ Delphine Wohrer, ${ }^{1}$ and Luigi Titomanlio ${ }^{1,4,5 *}$ \\ ${ }^{I}$ Department of Pediatric Emergency Care, APHP - Hopital Robert Debré, Paris, France; ${ }^{2}$ Department of Specialty and Integrated Medicine, The \\ Leeds Teaching Hospitals, NHS Trust, Leeds, UK; ${ }^{3}$ Department of Oncology, The Leeds Teaching Hospitals, NHS Trust, Leeds, UK; ${ }^{4}$ Pediatric \\ Migraine and Neurovascular Diseases Unit, APHP - Hopital Robert Debré, Paris, France; and ${ }^{5}$ Paris University, INSERM U1141, DHU Protect, \\ Paris, France
}

Migraine is one of the most frequent causes of primary headache and $9 \%$ of children suffer from migraines. Most children will continue to experience migraine attacks as adults, therefore it is imperative that we have a thorough understanding of this major health issue. This article considers the so-called abdominal variants of migraine, which are more commonly seen in children rather than adults: abdominal migraine, cyclic vomiting syndrome, and infantile colic. Other functional abdominal pain disorders such as irritable bowel syndrome and functional dyspepsia have also been linked to migraine in clinical studies. The common pathophysiological root of these diseases seems to be the gut-brain axis mechanism. Abdominal variants of migraine are considered pediatric precursors of migraine whereas the functional abdominal pain disorders related to migraine seem to share a pathophysiological root with no temporarily link as for today. In this review we aim to describe the epidemiological background, the current pathophysiological theories and the relationship of each disease to migraine. This review is the first to compile abdominal variants of migraine and functional abdominal pain disorders associated with migraine and we endeavor to elucidate the broad spectrum of migraine-related episodes in children.

(J Neurogastroenterol Motil 2021;27:482-494)

\section{Key Words}

Abdominal pain; Child; Gastrointestinal microbiome; Migraine disorders

\section{Introduction}

Migraine is one of the most frequent types of primary headache. In 2015, the Global Burden of Disease Study ranked it third as a cause of disability for men and women under 50 years of age. ${ }^{1}$ In 2017, the European prevalence of migraine was $20 \%$, which was a $6 \%$ increase compared to $1997 .^{2}$
In the pediatric population, the most recent epidemiological study ${ }^{3}$ estimated the prevalence of migraine to be $9.1 \%$, and crosssectional studies underline a constant increase of incidence of migraine with and without aura. ${ }^{4}$ Understanding the epidemiology and the prognosis of migraines in children and adolescents is important since the majority will continue to suffer into adulthood. ${ }^{3,5}$

Pediatric migraines differ from those experienced by adults, thus, their diagnosis can be challenging. Firstly, the diagnostic

Received: December 31, 2020 Revised: March 22, 2021 Accepted: April 8, 2021

(c) This is an Open Access article distributed under the terms of the Creative Commons Attribution Non-Commercial License (http://creativecommons. org/licenses/by-nc/4.0) which permits unrestricted non-commercial use, distribution, and reproduction in any medium, provided the original work is properly cited.

*Correspondence: Luigi Titomanlio, MD, PhD

Pediatric Emergency Department, Robert Debré Hospital, 48 Boulevard Serurier, 75019 Paris, France Tel: +33-140034005, Fax: +33-140034774, E-mail: luigi.titomanlio@rdb.aphp.fr 
criteria are different: ${ }^{6}$ episodes are commonly bilateral (whereas they are typically unilateral for adults) and shorter (sometimes less than one hour, especially for young children). ${ }^{7}$ Secondly, we now acknowledge a broad spectrum of migraine-related episodes which are more frequently seen in children: abdominal migraine (AM), cyclic vomiting syndrome (CVS), and infantile colic. ${ }^{8}$ These episodes can have a great impact on the child's and parent's quality of life, ${ }^{9}$ particularly since migraineur children are frequently afflicted with other comorbidities. Obesity, ${ }^{10}$ atopy, or allergic disease, ${ }^{11}$ a dysfunctional family situation, a low level of physical activity and physical or emotional abuse have all been associated with migraine and to its onset or progression. ${ }^{12}$ The relationship between migraine and functional abdominal pain has been discussed at length among adults $^{13-15}$ and identifies a connection between migraine and irritable bowel syndrome (IBS) and functional dyspepsia (FD), but further research is required among the pediatric population. ${ }^{16}$

These studies are evidence for the scholarly interest in understanding the pathophysiology behind migraines. The pathophysiology of migraine is a multifactorial phenomenon, ${ }^{17}$ dependent on genetic factors (more than thirty migraine-associated gene polymorphisms have been discovered), ${ }^{18}$ environmental factors (such as medication, diet, and stress) and metabolic factors (examples include

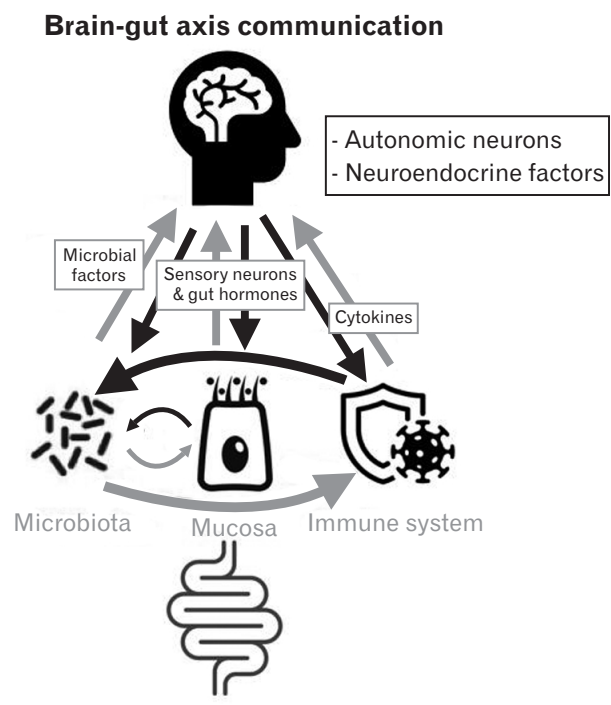

Figure. Gut-brain axis communication. Brain-gut communication describes the bidirectional messages from brain to gut microbiota, mucosa and immune system and vice versa, as well as the communication of the microbiota with the mucosa and the gut immune system. Microbial factors, gut hormones, sensory neurons, and cytokines can modify cerebral function. Autonomic neurons and neuroendocrine factors can modify the gut behavior in return. neuroendocrine function, the menstrual cycle, and pregnancy). The activation of the hypothalamus results in an alteration in thalamocortical circuits and brain connectivity, which subsequently leads to calcitonin gene-related peptide (CGRP) and pituitary adenylate cyclase-activating polypeptide (PACAP) release. The release of PACAP triggers intra-cerebral vasodilatation, ultimately causing the symptoms of migraine. Today, the role of CGRP in the gut-brain axis bidirectional communication is well recognized: CGRP has an antimicrobial action on gut bacterial strains (for instance, Escherichia coli, Enterococcus faecalis, and Lactobacillus acidophilus) and dysbiosis can increase the secretion of CGRP. ${ }^{19}$ The communication of the gut immune system, mucosa, and microbiota with the brain has been recently explored in great depth within the field of migraine research, particularly the association between functional abdominal pain disorders and migraine. ${ }^{19,20}$ The main communication pathways of the gut-brain axis are represented in Figure.

The diagnosis of migraine, its abdominal variants and functional abdominal pain can be challenging as they are often associated with each other. Early diagnosis is a good prognostic indicator of recovery for children and adolescents suffering from functional abdominal pain ${ }^{21}$ and migraines, ${ }^{5}$ thus the recognition of those conditions can have a great impact on children's quality of life.

To date, reviews have studied either the association of abdominal variants or the functional abdominal pain disorders with migraine (Table 1). ${ }^{13,22-30}$ In this review, we aim to define the different abdominal variants of migraine (AM, CVS, and infantile colic) and the functional abdominal pain disorders associated with migraine (IBS and dyspepsia) (Table 2), to describe their relation to migraine (Table 3), their epidemiology and their evolution within the pediatric population, and finally to discuss current therapeutic management.

\section{Abdominal Variants of Migraine}

AM, CVS, and infantile colic are gastrointestinal episodic syndromes classified as variants of migraine by the international classification of headache disorders (ICHD)-3 (beta version). ${ }^{8}$ Among the episodic syndromes, we also acknowledge benign paroxysmal vertigo and benign paroxysmal torticollis, but these 2 conditions will not be discussed here as they do not involve the gastrointestinal tract.

\section{Abdominal Migraine}

AM has been described in children since 1984 by Symon and Russel $^{31}$ and is now part of both the ICHD classification, and the 
Table 1. Previous Reviews on Abdominal Variants of Migraine and Functional Abdominal Pain Disorders' Association to Migraine

\begin{tabular}{|c|c|c|c|}
\hline Subject of study & Study & Authors & $\begin{array}{c}\text { Year of } \\
\text { publication }\end{array}$ \\
\hline \multirow[t]{5}{*}{ Abdominal variants of migraine } & $\begin{array}{l}\text { Migraine and childhood periodic syndromes in children and } \\
\text { adolescents }\end{array}$ & Gelfand $^{22}$ & 2013 \\
\hline & $\begin{array}{l}\text { Pediatric migraine and episodic syndromes that may be } \\
\text { associated with migraine }\end{array}$ & Spiri et $\mathrm{al}^{23}$ & 2014 \\
\hline & Migraine equivalents as part of migraine syndrome in childhood & Tarantino et al ${ }^{24}$ & 2014 \\
\hline & $\begin{array}{l}\text { Migraine variants or episodic syndromes that may be associated } \\
\text { with migraine and other unusual pediatric headache syndromes }\end{array}$ & Rothner and Parikh ${ }^{25}$ & 2016 \\
\hline & $\begin{array}{l}\text { Recurrent gastrointestinal disturbance: abdominal migraine and } \\
\text { cyclic vomiting syndrome }\end{array}$ & Irwin et $\mathrm{al}^{26}$ & 2017 \\
\hline Cyclic vomiting syndrome & Cyclic vomiting syndrome and migraine in children & Lin et $\mathrm{al}^{27}$ & 2011 \\
\hline \multirow[t]{3}{*}{ Infantile colic } & $\begin{array}{l}\text { The relation between migraine and infantile colic: a systematic } \\
\text { review and meta-analysis }\end{array}$ & Gelfand et $\mathrm{al}^{28}$ & 2015 \\
\hline & The link between infantile colic and migraine & Qubty and Gelfand ${ }^{29}$ & 2016 \\
\hline & $\begin{array}{l}\text { Relation between infantile colic and migraine as well as } \\
\text { tension-type headache: a meta-analysis }\end{array}$ & Zhang et $\mathrm{al}^{30}$ & 2019 \\
\hline Functional gastrointestinal disorders & $\begin{array}{l}\text { Migraine associated with gastrointestinal disorders: review of the } \\
\text { literature and clinical implications }\end{array}$ & van Hemert et $\mathrm{al}^{13}$ & 2014 \\
\hline
\end{tabular}

Rome IV classification. ${ }^{32}$ The diagnosis of AM can be challenging as it is at the crossroads of multiple organ's symptomatology. A positive clinical diagnosis of AM avoids unnecessary treatments and investigations.

A pragmatic clinical definition of AM in children is given by Angus-Leppan et $\mathrm{al}^{33}$ in 2018, adapted from definitions of Symon and Russel, ${ }^{31}$ ICHD-3 beta, ${ }^{8}$ and Rome IV $^{32}$ : (1) episodic central abdominal pain, usually lasting $>1$ hour, (2) episodes interfere with normal activity, (3) episodes occur with one or more of pallor, anorexia, nausea, vomiting, photophobia, headache, or are associated with other episodic syndromes (particularly CVS well between episodes), and (4) normal physical and developmental examination.

Children with AM report similar triggers (stress and fatigue) and relieving factors (rest and sleep) to migraineurs. ${ }^{34}$ One key to the diagnosis is the absence of headache during episodes. Vomiting symptoms are also less severe than in CVS. The prevalence of AM is generally reported to be around $5 \%$ to $9 \%$ of the pediatric population $^{34,35}$ but increases in children with a family history of migraine or depression. ${ }^{34-37}$ It is also higher among girls, with a reported sex ratio around 1.6/1 in Abu-Arafeh's first prevalence study in $1995 .^{34}$

In the adult population, the diagnosis of AM remains very uncommon and few case reports have been published to date. ${ }^{38}$ Roberts and deShazo ${ }^{39}$ reported a cohort of 13 patients (11 from the medical literature and 2 from their clinic) and analyzed their symptoms by the IHCD-2 and the Rome III classifications of pe- diatric AM: 10 of their patients met some criteria for AM. Ninety percent of them had a family history of migraine. ${ }^{39}$ Their findings suggest considering AM in the differential diagnosis of recurrent abdominal pain in adults, especially if a family history of migraine is observed.

With respect to the pathophysiology hypothesis, in 2016, Devanarayana et $\mathrm{al}^{40}$ studied gastric motility of $\mathrm{AM}$ patients compared with control patients and showed that gastric and antral motility parameters were significantly lower in children with AM. They also noticed a significant correlation between symptom severity and gastric motility, a field of study within gut-brain axis diseases since it aids our understanding of the central innervation of the gut. Moreover, alteration of gut permeability has been proven in AM patients. In a study of $11 \mathrm{AM}$ patients and 9 control children, Bentley et $\mathrm{al}^{37}$ showed that the mucosal permiability of small intestine was increased in AM patients. Furthermore, they longitudinally followed 3 AM patients and noticed a decrease in gut permeability correlated to the improvement of the AM symptoms. In some patients, the mucosal response to food allergens evidently seemed to trigger AM. ${ }^{37}$ The communication between the enteric and the central nervous system (CNS), best known as the gut-brain axis, helps us to understand how these intestinal changes are related to migraine. ${ }^{41}$

Children with AM have an excellent prognosis, with a majority demonstrating complete resolution of symptoms. It is unclear what causes AM to persist into adulthood since there are few case reports 
Table 2. Abdominal Variants of Migraine and Functional Abdominal Pain Disorders Associated to Migraine

\begin{tabular}{|c|c|c|}
\hline Pathology & Clinical definition & Source \\
\hline Abdominal migraine & $\begin{array}{l}\text { Episodic central abdominal pain, usually lasting }>1 \text { hour } \\
\text { Episodes interfere with normal activity } \\
\text { Episodes occur with one or more of pallor, anorexia, nausea, vomiting, } \\
\text { photophobia, and headache, or are associated with other episodic syndromes } \\
\text { (particularly cyclic vomiting syndrome and migraine limb pain) } \\
\text { The person is well between episodes and has a normal physical and developmental } \\
\text { examination }\end{array}$ & $\begin{array}{l}\text { Adapted from ICHD-3 } \mathrm{b}^{\mathrm{a}} \\
\text { and Rome IV classification }\end{array}$ \\
\hline Cyclic vomiting syndrome & $\begin{array}{l}\text { Recurrent episodic attacks of intense nausea and vomiting, usually stereotypical in } \\
\text { the individual and with predictable timing of episodes } \\
\text { Attacks may be associated with pallor and lethargy } \\
\text { There is a complete resolution of symptoms between attacks } \\
\text { The diagnostic criteria include all of the following: } \\
\text { Nausea and vomiting occurring at least } 4 \text { times per hour } \\
\text { Attacks lasting from } 1 \text { hour up to } 10 \text { days } \\
\text { Attacks occurring } 1 \text { week apart }\end{array}$ & ICHD-3b criteria \\
\hline Infantile colic & $\begin{array}{l}\text { A. Recurrent episodes of irritability, fussing, or crying from birth to } 4 \text { months of } \\
\text { age, fulfilling criterion B: } \\
\text { B. Both of the following: } \\
\text { Episodes last for } 3 \text { hours per day } \\
\text { Episodes occur on } 3 \text { days per week for } 3 \text { weeks } \\
\text { Not attributed to another disorder }\end{array}$ & ICHD-3b criteria \\
\hline Irritable bowel syndrome & $\begin{array}{l}\text { Abdominal pain at least } 4 \text { days per month associated with one or more of } \\
\text { the following: } \\
\text { Related to defecation } \\
\text { A change in frequency of stool } \\
\text { A change in form (appearance) of stool } \\
\text { In children with constipation, the pain does not resolve with resolution of the } \\
\text { constipation (in this case, the child has functional constipation) } \\
\text { After appropriate evaluation, the symptoms cannot be fully explained by another } \\
\text { medical condition }\end{array}$ & Rome IV classification \\
\hline Functional dyspepsia & $\begin{array}{l}\text { One or more of the following symptoms at least } 4 \text { days per month: } \\
\text { Postprandial fullness } \\
\text { Early satiation } \\
\text { Epigastric pain or burning not associated with defecation } \\
\text { After appropriate evaluation the symptoms cannot be fully explained by another } \\
\text { medical condition }\end{array}$ & Rome IV classification \\
\hline
\end{tabular}

${ }^{\mathrm{a}}$ International classification of headache disorders (ICHD)-3 (beta version).

and small sample sizes. ${ }^{39}$ Although AM symptoms ultimately tend to evanesce, almost $70 \%$ of children will go on to develop classic migraine or recurrent abdominal pain syndrome. ${ }^{42,43}$

$\mathrm{AM}$ is now considered to be a pediatric precursor of migraine, consequently experts tend to extrapolate the usual migraine treatment to AM. However, to date, only 1 randomized control trial has been published within the field of pediatrics: pizotifen (a serotonin agonist) reduces the duration and the severity of AM when used as a preventive treatment ${ }^{44}$ Retrospective data on propranolol (a $\beta$ blocker), cyproheptadine (an antihistamine), and flunarizine (a calcium channel blocker) as preventive therapies also seem to show a reduction in the frequency and severity of AM episodes. ${ }^{33}$ Lifestyle modifications are also recommended to prevent migraine crises.

\section{Cyclic Vomiting Syndrome}

CVS is part of the episodic syndromes associated with migraine as defined by the ICHD-3b classification. ${ }^{8}$ The symptoms of CVS are very typical and have been recently defined $a^{8}$ : (1) recurrent 
Table 3. Pathophysiological, Clinical, and Temporal Relation of Abdominal Migraine, Cyclic Vomiting Syndrome, Infantile Colic, Irritable Bowel Syndrome, and Functional Dyspepsia With Migraine

\begin{tabular}{|c|c|c|c|}
\hline Pathology & Common physiopathology & Common clinical features & Temporal course \\
\hline Abdominal migraine & $\begin{array}{l}\text { Gastric motility alteration } \\
\text { Increased gut permeability }\end{array}$ & $\begin{array}{l}\text { Triggering/relieving factors } \\
\text { Family history of migraine }\end{array}$ & Precursor of migraine in adulthood \\
\hline Cyclic vomiting syndrome & $\begin{array}{l}\text { Neuronal hyperexcitation } \\
\text { Gastric motility alteration }\end{array}$ & $\begin{array}{l}\text { Anxiety/depression in personal or } \\
\text { family history }\end{array}$ & Precursor of migraine in adulthood \\
\hline Infantile colic & $\begin{array}{l}\text { Microbiota modification } \\
\text { Increased gut inflammation and } \\
\text { permeability }\end{array}$ & $\begin{array}{l}\text { Anxiety/depression in personal or } \\
\text { family history } \\
\text { Family history of migraine }\end{array}$ & Precursor of migraine in adulthood \\
\hline Irritable bowel syndrome & $\begin{array}{l}\text { Visceral hyperalgesia } \\
\text { Increased gut permeability and } \\
\text { immune-allergic response }\end{array}$ & $\begin{array}{l}\text { Amelioration of symptoms with } \\
\text { FODMAPs exclusive regime } \\
\text { Anxiety/depression in personal } \\
\text { or family history }\end{array}$ & Co-occurrence with migraine \\
\hline Functional dyspepsia & $\begin{array}{l}\text { Gastric motility alteration } \\
\text { Visceral hyperalgesia } \\
\text { Increased immune-allergic response }\end{array}$ & $\begin{array}{l}\text { Anxiety/depression in personal } \\
\text { history }\end{array}$ & Co-occurrence with migraine \\
\hline
\end{tabular}

FODMAPs, fermentable oligosaccharides, disaccharides, monosaccharides, and polyols.

episodic attacks of intense nausea and vomiting, usually stereotypical to the individual and with predictable timing of episodes, (2) attacks may be associated with pallor and lethargy, and (3) there is a complete resolution of symptoms between attacks.

The diagnostic criteria include all of the following: (1) nausea and vomiting occurring at least 4 times per hour, (2) attacks lasting from 1 hour up to 10 days, and (3) attacks occurring 1 week apart.

The prodromal phase is characterized by intense nausea, pallor, tiredness, and abdominal pain. The vomiting phase is very intense within the first hour with a median frequency of 6 vomiting episodes per hour, declining during the next 4 hours to 8 hours. The recovery phase begins with the remission of nausea, continuing until recovery of appetite and strength. In $75 \%$ of children, the attacks begin between midnight and early morning. ${ }^{45}$

The prevalence of CVS is estimated between $0.3 \%$ and $6.1 \%^{47}$ making it less frequent in the pediatric population than migraine or AM. The pathophysiology of CVS remains unclear but different possibilities have been researched recently. Mitochondrial abnormalities have been explored as a maternal inheritance of CVS and 2 mitochondrial polymorphisms have been found to be highly associated with migrainous headaches and $\mathrm{CVS}^{48}$ As with the migrainous pathophysiology, hypothalamic function is also influential in CVS as the control center of the CNS. In 2016, Ellingsen et $\mathrm{al}^{49}$ published the first functional MRI study to characterize altered brain connectivity in the insular cortex, the region of the brain involved in disease mechanisms responsible for both CVS and adult migraine. Autonomic dysfunction studies show a strong correlation between
CVS, postural orthostatic tachycardia and an aberrant heart rate variability. ${ }^{50}$ Gastric motility has been explored in pediatric and adult patients suffering from CVS or migraine and mostly shows acceleration of gastric emptying, which implies altered autonomic function.

In comparison to AM, CVS has also been explored in the adult population and it is interesting to compare these cohorts. As children mature, their symptoms generally ameliorate or resolve; attacks become less intense and shorter in duration. In a Taiwanese pediatric study, ${ }^{51} 9$ out of 24 patients were symptom-free 4 years after diagnosis. On the other hand, newly diagnosed adult patients tend to have longer and more intense episodes than children ${ }^{52}$ but the vomiting pattern previously described remains consistent. ${ }^{53}$ Time to diagnosis is around 2 years for children whereas it is around 8 years for adults. The quality of life of CVS school-age children is often significantly affected; $85 \%$ had absences from school in the previous year due to their condition. ${ }^{45}$ An early diagnosis improves the quality of life of children suffering from CVS. ${ }^{54}$ Considering these data, the psychiatric profile of CVS patients has also been explored, ${ }^{55}$ with 1 study finding that $47 \%$ of children with CVS suffer from anxiety disorders. It is important to note that in this study parents reported significantly more psychiatric symptoms in their children than the children themselves. The hypothesis of anxiety transmission has also been explored for migraine and infantile colic.

The treatment of CVS in children is the same as for migraine: lifestyle modifications, plus medical management such as propranolol, flunarizine or mirtazapine, or anticonvulsants such as topira- 
mate, phenobarbital, or levetiracetam. Antiemetic treatment such as aprepitant can also be used as a preventive treatment in CVS. ${ }^{56}$

Prognostically, it has been demonstrated that between $30 \%$ and $50 \%$ of CVS patients will develop migraines, ${ }^{57}$ with children diagnosed at an early age and those with more severe symptoms being the most likely to become migraineurs. Moreover, the clinical features (nausea, vomiting, and phono-photo-phobia), the periodicity, the triggers (stress and sleep deprivation) allow us to consider CVS as an equivalent and a precursor of migraine in children.

\section{Infantile Colic}

Infantile colic has recently been added to the ICHD classification, first appearing in the 2013 ICHD-3b. ${ }^{8}$ Infantile colic was first described and characterized by Wessel et $\mathrm{al}^{58}$ in 1954 to describe the "paroxysmal fussing" of infants under 4 months of age. It describes "paroxysmal fussing" or "infantile colic" as "possibly one of the earliest somatic responses to the presence of tension in the environment" leading to years of understanding infantile colic as a type of psychosomatic disorder. The ICHD classification's diagnosis criteria are as follows: (1) A. Recurrent episodes of irritability, fussing, or crying from birth to 4 months of age, fulfilling criterion B; (2) B. Both of the following: episodes last for 3 hours per day and episodes occur on 3 days per week for 3 weeks; and (3) not attributed to another disorder.

A systematic review and meta-analysis of 2017 by Wolke et $\mathrm{al}^{59}$ studied the prevalence and crying duration of infantile colic and reported a high prevalence, $17-25 \%$, of infantile colic under 6 weeks, decreasing shortly after 6 weeks to $11 \%$ and to $0.6 \%$ by $10-12$ weeks.

The pathophysiology of infantile colic is also a good model of the gut-brain axis mechanism. The influence of microbiota on infantile colic has been investigated by means of stool studies ${ }^{60}$ and on the effect of intrapartum ${ }^{61}$ or neonatal antibiotic treatment. ${ }^{62}$ These studies show an increased risk of infantile colic for children who were administered antibiotics at birth or in the first week. It is widely recognized that antibiotic treatment modifies the gut and vaginal microbiota, and a review by Zeevenhooven et $\mathrm{al}^{63}$ studying children with colic identified a lower diversity in their intestinal microbiota, an abundance of microorganisms such as Escherichia, Enterobacter, and Klebsiella and a delayed or altered colonization by Lactobacillus spp. It has been demonstrated that Lactobacillus spp. has a protective effect against gas production bacteria such as Escherichia, Enterobacter, and Klebsiella. ${ }^{64}$ Recently, studies have also highlighted the presence of fecal calprotectin in stool samples from children suffering from infantile colic. ${ }^{60}$ Fecal calprotectin is a biochemical marker that indicates the presence of inflammation in the intestinal tract. Higher levels of IL-8, MCP-1, and MIP-1 $\beta$ have also been found in blood samples of colicky children, suggesting low grade systemic inflammation. ${ }^{65}$

Factors influencing the microbiota of children and their mothers have thus been widely explored by researchers, with particular attention paid to maternal medical and psychological status. Maternal health conditions such as obesity, ${ }^{66}$ migraine,${ }^{66}$ tobacco consumption, ${ }^{67}$ anxiety, ${ }^{68}$ and depression represent risk factors for infantile colic. Paternal support to the expectant mothers, ${ }^{69}$ familial support and a couple's level of happiness have also been linked to a lower risk of infantile colic. Moreover, paternal depression has been linked to infantile colic. ${ }^{70}$

The complexity of infantile colic is also influenced by an immature CNS. Indeed, the prevalence and the intensity of infantile colic decreases at around 8 weeks of age, which corresponds to the transition from reflex mechanisms to behavior controlled by the cerebral cortex. ${ }^{63}$ A perfect example of the effects of CNS immaturity is the preterm population where the risk of infantile colic is increased, and some studies have shown that increased prevalence corresponds with the degree of prematurity. ${ }^{71}$ Similarly, newborns with a lower birth weight tend to suffer more with colic. ${ }^{72}$ The immature enteric nervous system may contribute to infantile colic by way of gut dysmotility, which leads to altered mucus secretion and modification of microbial composition.

Although the pathophysiology of infantile colic is complex, there is a better understanding of the outlook for children with colic. In follow-up studies of children between 5 years old ${ }^{73}$ and 10 years old, ${ }^{74}$ an increase in sleep disorders, aggression or anger, and ADHD have been observed. ${ }^{75}$ Concerning somatic health problems, infantile colic has now been linked to recurrent abdominal pain ${ }^{74}$ and migraine $e^{29,30,76,77}$ in numerous studies. The first case report linking migraine to infantile colic was published by Katerji and Painter ${ }^{78}$ in 1994 and describes an infantile migraine presenting as colic. In 2013, a case-control study of 679 patients showed that children with migraine were more likely to have experienced infantile colic (OR, 6.61; CI 95\%, 4.38-10.00; $P<0.001)^{77}$ and other study has reached the same conclusion. ${ }^{76}$ This hypothesis has been strengthened by studies linking parental migraine to infantile colic, ${ }^{79}$ allowing us to consider the possibility that these phenomena are symptoms on the same spectrum. ${ }^{29,80}$

Concerning the treatment of infantile colic, it has been at an impasse for many years. A recent systematic review from $\mathrm{Hjern}$ et $\mathrm{al}^{81}$ found moderate evidence to support the efficacy of Lactobacillus reuteri DSM 17938 in the treatment of infantile colic (favorable out- 
come in 3 out of 4 randomized control trials). On the other hand, Hjern et $\mathrm{al}^{81}$ reported that dietary modification (formula enriched with Lactobacillus) failed to show improvement of symptoms.

\section{Functional Abdominal Pain Disorders Asso- ciated With Migraine}

The Rome IV classification categorizes the functional gastrointestinal disorders (FGID) in children into 3 subtypes: (1) functional abdominal pain disorders, (2) functional nausea and vomiting disorders, and (3) functional defecation disorders. ${ }^{32}$

There are 3 subtypes of functional abdominal pain disorders: IBS, FD, and AM. Here we are interested in IBS and FD as they are the only 2 that studies have shown as being linked to migraine. ${ }^{13,14,16}$ They are not considered as abdominal variants of migraine, in comparison to $\mathrm{AM}$, in the ICHD-3b as, so far as is known, they coexist with migraine, without being temporarily linked to it. The most frequent FGID identified in toddlers is functional constipation $^{82}$ which is part of the functional defecation disorders, but again with no link to migraine proven to date.

\section{Irritable Bowel Syndrome}

The Rome IV classification ${ }^{32}$ defines IBS in children as: (1) abdominal pain in at least 4 days per month associated with 1 or more of the following: (a) related to defecation, (b) a change in frequency of stool, and (c) a change in form (appearance) of stool; (2) in children with constipation, the pain does not resolve with resolution of the constipation (in this case, the child has functional constipation); and (3) after appropriate evaluation, the symptoms cannot be fully explained by other medical conditions.

IBS can be divided into subtypes reflecting the predominant stool pattern: IBS with constipation, IBS with diarrhea, IBS with constipation and diarrhea, and unspecified IBS.

According to a meta-analysis of 16 studies on the prevalence of IBS in Asian children, the prevalence ranges from 2.8\% to $25.7 \%$ with a pooled prevalence of $12.4 \% .^{83}$ The prevalence risk ratio for girls to boys is 1.39 . The prevalence of IBS in children from the Mediterranean region of Europe is evaluated at $4.0 \%{ }^{84}$

IBS etiology is most likely multi-factorial involving biological, psychological, and social factors. ${ }^{85}$ Visceral hyperalgesia (or hypersensitivity) and visceral hypervigilance are key concepts in current research on pathophysiological mechanisms of IBS ${ }^{86}$ Brain imaging studies show that the neural processing of visceral stimuli is altered in IBS. ${ }^{85}$ There is also growing evidence to suggest that peripheral immune mechanisms and disturbed neuro-immune communication could play a role in the pathophysiology of visceral hyperalgesia. The contribution of both stress and negative emotions on symptom frequency and severity has been studied for some time now amongst children ${ }^{87}$ As a gut-brain axis disorder, the influence of microbiota has also been studied in IBS and Hollister et a ${ }^{88}$ observed a significant difference in bacterial species (Flavonifractor plautii and Lachnospiraceae bacterium 7_1_58FAA) in IBS cases compared to control patients. Using artificial intelligence programming, Hollister et $\mathrm{al}^{88}$ manage to distinguish stool features that could help diagnose IBS. The neuroimmune system, an element of the gut-brain axis, has also been explored and found to be activated in children suffering from IBS. Increased fecal granins in the stool, ${ }^{89}$ increased gut permeability, ${ }^{90,91}$ and increased serum brainderived neurotrophic factor (BDNF) and proBDNF have been highlighted recently in pediatric studies.

The relationship between food allergies and recurrent abdominal pain, IBS in particular, has also been widely explored. ${ }^{92}$ Some studies have shown an improvement in the severity and the frequency of pain in pediatric patients under fermentable oligosaccharides, disaccharides, monosaccharides, and polyols (FODMAPs) exclusive-regime. ${ }^{93}$ In addition, the role of food on their symptoms is often expressed by IBS patients, whether they are adults or children. ${ }^{94}$

The role of personal beliefs and psychological factors is proven to impact the severity of symptoms. The transmission of somatic symptoms inside the family nucleus is part of the difficulty in acknowledging the symptoms of IBS patients, as shown by van Tilburg et $\mathrm{al}^{95}$ with mothers and fathers of IBS patients also tending to report more symptoms concerning themselves. ${ }^{96}$ The presence of adverse life events, inducing fear, increases the risk of IBS symptoms presenting in children. ${ }^{97}$ Thus, anxiety and depression are predictors of abdominal pain severity in IBS patients. ${ }^{87}$ In some families, the secondary benefit of having abdominal pain, such as providing an excuse to avoid household tasks, increases the risk of IBS in low-birth-weight children. ${ }^{98}$ These studies show the difficulties in understanding the underlying causes of such a multi-factorial syndrome.

The treatment of IBS in children is still mostly dominated by non-pharmaceutical interventions such as parental education, diet (FODMAP exclusion, gluten free or increase of fiber consumption) or behavioral therapy. Unfortunately, most of the trials regarding pharmaceutical therapies study children suffering from functional abdominal pain and not IBS or FD alone. ${ }^{98-100} \mathrm{~A}$ lack of clear evidence makes it very difficult to prioritize 1 treatment over another among: antiemetics (domperidone), antidepressants (tricyclic 
or selective serotonin reuptake inhibitors), acid suppressing agents, antispasmodics, and antihistamines. However, probiotics seem to be effective in treating IBS in children with an estimated number need to treat of 4 according to a meta-analysis of 19 randomized control trials (RCTs). ${ }^{101}$

Regarding the evolution of IBS in children, the majority (60\%) will observe the disappearance of their symptoms over 2 years following the diagnosis, regardless of age, sex, and impact of symptoms. ${ }^{102,103}$ As exposed previously for abdominal variants of migraine, the initial diagnosis of IBS increases the chance of a symptom's resolution, which makes the positive diagnosis a very important step in the support of IBS patients. ${ }^{21}$ Le Gal et $\mathrm{al}^{16}$ showed a 3.47 OR $(95 \% \mathrm{CI}, 1.81-6.62 ; P=0.0002)$ of IBS in child migraineurs in a retrospective case-control study of 1072 patients. Retrospective and prevalence studies that were interested in the prevalence of IBS and FGID in adult and children migraineurs show an important correlation between these 2 disorders. ${ }^{13-16,104}$ In a large United States IBS cohort of 97000 patients a $60 \%$ higher odds of migraine was demonstrated in the IBS population compared to control patients in an adult population. ${ }^{15}$ In the adult population, the symptoms are the same as defined for children in the Rome IV classification. In a recent review on the prevalence of IBS in adults, the Rome Foundation refuses to give a pooled percentage for IBS since the mean prevalence in individual countries ranged from $1.1 \%$ (France and Iran) to $35.5 \%$ (Mexico). ${ }^{105}$ To shed light on the pathophysiology of IBS studies focusing on regional and cross-cultural differences are needed.

\section{Functional Dyspepsia}

The diagnosis criteria for FD in children, as defined by the Rome IV classification, ${ }^{32}$ must include one or more of the following symptoms at least 4 days per month: (1) postprandial fullness, (2) early satiation, (3) epigastric pain or burning not associated with defecation, and (4) after appropriate evaluation the symptoms cannot be fully explained by other medical conditions.

Within FD, we describe 2 subtypes $^{32}$ : postprandial distress syndrome and epigastric pain syndrome. The postprandial distress syndrome includes bothersome postprandial fullness or early satiation that prevents finishing a regular meal, which can be associated with abdominal bloating, postprandial nausea, or excessive belching. The epigastric pain syndrome is defined as bothersome pain or burning localized to the epigastrium, without a retrosternal component and the ingestion of a meal being a trigger or an improvement factor. As for previous exposed syndromes, the diagnosis of FD requires clinical examination and history only. However, FD and gastroesophageal reflux can be difficult to distinguish, so the requirement of esophagogastroduodenoscopy in the diagnosis of FD has been debated. ${ }^{106}$ The Rome IV classification considers there is no compelling evidence to require an esophagogastroduodenoscopy in order to make a diagnosis of FD in the pediatric population. ${ }^{32}$

The prevalence of FD is described around $7.6 \%$ of children, using the Rome IV diagnostic criteria.

Concerning FD in the adult population, a recent review by Wauters et $\mathrm{al}^{108}$ consider it as the most common functional upper gastrointestinal disorder affecting $15 \%$ of the general population. Its symptoms do not differ in the Rome IV classification for either adults or children.

The pathophysiology of FD still remains unclear. It is a complex combination of physiologic, genetic, environmental, and psychological factors. ${ }^{109}$ We can distinguish 2 major mechanisms: gastric motility abnormalities and impaired gastric accommodation and visceral hypersensitivity. ${ }^{110}$ Gastric accommodation is defined by the ability of the stomach to distend appropriately during a meal with an increase in gastric volume in the absence of increased gastric pressure. Gastric motility can be explored by a number of different methods (sodium acetate breath tests, ${ }^{111}$ gastric emptying scintigraphy, ${ }^{112}$ or electrogastrography ${ }^{113}$ for example) and can be compared in $\mathrm{FD}$ and control patients in the pediatric and adult populations. Studies have shown delayed gastric emptying, ${ }^{11,112}$ antral hypomotility, ${ }^{113}$ and a negative correlation between gastric emptying rate and severity of abdominal pain ${ }^{114}$ among dyspeptic patients. This impaired accommodation may be linked to abnormalities of the vagal reflex and intrinsic inhibitory innervation. ${ }^{115}$ Studies on adults and children highlighted abnormal gastric sensorimotor function. ${ }^{116}$ The visceral hypersensitivity to gastric distention in FD can be considered as a model of a gut-brain axis disorder. The presence of inflammatory cells (eosinophilia and high mast cell density) can be found in the stomach and duodenum of children suffering from $\mathrm{FD},{ }^{117}$ especially if they are also suffering from headaches. ${ }^{118} \mathrm{An}$ altered intestinal permeability, as observed in IBS or AM, was not observed in FD patients. ${ }^{119}$ The role of Helicobacter pylori on FD and migraine has also been studied. In 2016, a meta-analysis of 25 RCT and 5555 adult patients with FD showed a 1.23-fold improvement of symptoms after $H$. Pylori's eradication at long-term follow-up. ${ }^{120}$ Moreover, a cohort of 305 adult dyspeptic patients showed a significantly positive association between $H$. Pylori and migraine and family history of headache. ${ }^{121}$ Concerning treatment, in the pediatric population, a systematic review of three RCTs studying pharmaceutical options to treat FD found no evidence to support the use of pharmacological drugs. ${ }^{122}$ 
An important intrinsic role for psychosocial factors and psychiatric disorders, especially anxiety and depression, has been described in the etiopathogenesis of $\mathrm{FD}$, in addition to their putative influence on health care-seeking behavior. Around $50 \%$ of FD patients show high anxiety score responses. ${ }^{119}$

Finally, for a few years, studies have underlined a link between FD (postprandial distress syndrome or epigastric pain syndrome) and migraine in the pediatric population. Di Stefano et $\mathrm{al}^{123}$ were interested in the prevalence and pathophysiology of migraine in functional dyspeptic adult patients and demonstrated $54 \%$ of epigastric pain syndrome patients and $76 \%$ of postprandial distress syndrome patients also suffered from migraine. Among the postprandial distress syndrome patients, the severity of fullness and early satiation correlated to the severity of migraine. ${ }^{123}$ Cohort studies also showed an association between primary headache and FD: $25 \%$ of FD children declared having headache more than 3 times a month on an internet questionnaire survey, ${ }^{124} 60 \%$ of adults migraineurs suffer from FD in a prevalence study, ${ }^{125}$ and Lankarani et a ${ }^{14}$ found a 1.68 OR $(P<0.001)$ for FD among 1038 adults migraineurs in Iran. Le Gal et al ${ }^{16}$ calculated an odds ratio of 10 for FD among children suffering from migraine.

\section{Conclusion}

The aim of this review is to summarize the recent knowledge on abdominal variants of migraine and functional abdominal pain disorders associated to migraine, as they appear to be part of a wider spectrum of diseases now being explored as brain-gut disorders (Table 2). Migraine and related syndromes have a great impact on the quality of life of children and their future as adults. The understanding of pathophysiological mechanisms underlying these conditions is crucial in order to improve diagnosis, treatment, and followup in these children.

In this review, we discussed whether the inflammatory mediators, gut microbiota profile, neuropeptides, serotonin pathway, stress hormones, and nutritional substances which are related with brain-gut axis could be a pathophysiology of abdominal variants of migraine and functional abdominal pain disorders associated to migraine. AM, CVS, infantile colic, and IBS appear to be mediated by neuroinflammatory and neuroimmune patterns that can also be found in migraine. For FD, alterations in motility and gastric accommodation are among the main hypotheses. Therefore, it is possible that alterations of the gut-brain axis could be involved in the underlying mechanism for all of the abdominal syndromes associated with migraine.

\section{Financial support: None.}

\section{Conflicts of interest: None.}

Author contributions: Léa LenglarT and Luigi Titomanlio: concept and design, drafting the paper, and revising the paper; Léa LenglarT, Delphine Wohrer, and Caroline Caula: collecting articles and revising the paper; and Thomas Moulding and Annabel Lyles: English revision of the paper.

\section{References}

1. Steiner TJ, Stovner LJ, Vos T. GBD 2015: migraine is the third cause of disability in under 50s. J Headache Pain 2016;17:104.

2. Deuschl G, Beghi E, Fazekas F, et al. The burden of neurological diseases in Europe: an analysis for the Global Burden of Disease Study 2017. Lancet Public Health 2020;5:e551-e567.

3. Wöber-Bingöl Ç. Epidemiology of migraine and headache in children and adolescents. Curr Pain Headache Rep 2013;17:341.

4. Anttila P. Long-term trends in the incidence of headache in finnish schoolchildren. Pediatrics 2006;117:e1197-e1201.

5. Kienbacher C, Wöber C, Zesch H, et al. Clinical features, classification and prognosis of migraine and tension-type headache in children and adolescents: a long-term follow-up study. Cephalalgia 2006;26:820-830.

6. McAbee GN, Morse AM, Assadi M. Pediatric aspects of headache classification in the international classification of headache disorders-3 (ICHD-3 beta version). Curr Pain Headache Rep 2016;20:7.

7. Abu-Arafeh I, Callaghan M. Short migraine attacks of less than $2 \mathrm{~h} \mathrm{du}-$ ration in children and adolescents. Cephalalgia 2004;24:333-338.

8. Headache Classification Committee of the International Headache Society (IHS). The international classification of headache disorders, 3rd edition (beta version). Cephalalgia 2013;33:629-808.

9. Koller LS, Diesner SC, Voitl P. Quality of life in children and adolescents with migraine: an Austrian monocentric, cross-sectional questionnaire study. BMC Pediatr 2019;19:164.

10. Eidlitz Markus T, Toldo I. Obesity and migraine in childhood. Curr Pain Headache Rep 2018;22:42.

11. Özge A, Uluduz D, Bolay H. Co-occurrence of migraine and atopy in children and adolescents: myth or a casual relationship? Curr Opin Neurol 2017;30:287-291.

12. Russo A, Bruno A, Trojsi F, Tessitore A, Tedeschi G. Lifestyle factors and migraine in childhood. Curr Pain Headache Rep 2016;20:9.

13. van Hemert S, Breedveld AC, Rovers JMP, et al. Migraine associated with gastrointestinal disorders: review of the literature and clinical implications. Front Neurol 2014;5:214.

14. Lankarani KB, Akbari M, Tabrizi R. Association of gastrointestinal functional disorders and migraine headache: a population base study. Middle East J Dig Dis 2017;9:139-145.

15. Cole JA, Rothman KJ, Cabral HJ, Zhang Y, Farraye FA. Migraine, fibromyalgia, and depression among people with IBS: a prevalence study. BMC Gastroenterol 2006;6:26. 
16. Le Gal J, Michel JF, Rinaldi VE, et al. Association between functional gastrointestinal disorders and migraine in children and adolescents: a case-control study. Lancet Gastroenterol Hepatol 2016;1:114-121.

17. Charles A. The pathophysiology of migraine: implications for clinical management. Lancet Neurol 2018;17:174-182.

18. Gormley P, Anttila V, Winsvold BS, et al. Meta-analysis of 375,000 individuals identifies 38 susceptibility loci for migraine. Nat Genet 2016;48:856-866.

19. Arzani M, Jahromi SR, Ghorbani Z, et al. Gut-brain axis and migraine headache: a comprehensive review. J Headache Pain 2020;21:15.

20. Mesa MD, Loureiro B, Iglesia I, et al. The evolving microbiome from pregnancy to early infancy: a comprehensive review. Nutrients 2020;12:133.

21. Trivić I, Hojsak I. Initial diagnosis of functional gastrointestinal disorders in children increases a chance for resolution of symptoms. Pediatr Gastroenterol Hepatol Nutr 2018;21:264-270.

22. Gelfand AA. Migraine and childhood periodic syndromes in children and adolescents. Curr Opin Neurol 2013;26:262-268.

23. Spiri D, Rinaldi VE, Titomanlio L. Pediatric migraine and episodic syndromes that may be associated with migraine. Ital J Pediatr 2014;40:92.

24. Tarantino S, Capuano A, Torriero R, et al. Migraine equivalents as part of migraine syndrome in childhood. Pediatr Neurol 2014;51:645-649.

25. Rothner AD, Parikh S. Migraine variants or episodic syndromes that may be associated with migraine and other unusual pediatric headache syndromes. Headache 2016;56:206-214.

26. Irwin S, Barmherzig R, Gelfand A. Recurrent gastrointestinal disturbance: abdominal migraine and cyclic vomiting syndrome. Curr Neurol Neurosci Rep 2017;17:21.

27. Lin YP, Ni YH, Weng WC, Lee WT. Cyclic vomiting syndrome and migraine in children. J Formos Med Assoc 2011;110:382-387.

28. Gelfand AA, Goadsby PJ, Allen IE. The relationship between migraine and infant colic: a systematic review and meta-analysis. Cephalalgia 2015;35:63-72.

29. Qubty W, Gelfand AA. The link between infantile colic and migraine. Curr Pain Headache Rep 2016;20:31.

30. Zhang D, Zhang Y, Sang Y, Zheng N, Liu X. The relationship between infant Colic and migraine as well as tension-type headache: a metaanalysis. Pain Res Manag 2019;2019:8307982.

31. Symon DN, Russell G. Abdominal migraine: a childhood syndrome defined. Cephalalgia 1986;6:223-228.

32. Hyams JS, Di Lorenzo C, Saps M, Shulman R, Staiano A, van Tilburg M. Childhood functional gastrointestinal disorders: child/adolescent. Gastroenterology 2016;150:1456-1468, e2.

33. Angus-Leppan H, Saatci D, Sutcliffe A, Guiloff RJ. Abdominal migraine. BMJ 2018;360:k179.

34. Abu-Arafeh I, Russell G. Prevalence and clinical features of abdominal migraine compared with those of migraine headache. Arch Dis Child 1995;72:413-417.

35. Mortimer MJ, Kay J, Jaron A. Clinocal epidemiology of childhood abdominal migraine in an urban general practice. Dev Med Child Neurol 2008;35:243-248.

36. Mortimer MJ, Kay J, Jaron A, Good PA. Does a history of maternal migraine or depression predispose children to headache and stomachache? Headache 1992;32:353-355.

37. Bentley D, Kehely A, al-Bayaty M, Michie CA. Abdominal migraine as a cause of vomiting in children: a clinican's view. J Pediatr Gastroenterol Nutr 1995;21(suppl 1):S49-S51.

38. Kunishi $\mathrm{Y}$, Iwata $\mathrm{Y}$, Ota M, et al. Abdominal migraine in a middle-aged woman. Intern Med 2016;55:2793-2798.

39. Roberts JE, deShazo RD. Abdominal migraine, another cause of abdominal pain in adults. Am J Med 2012;125:1135-1139.

40. Devanarayana NM, Rajindrajith S, Benninga MA. Abdominal migraine in children: association between gastric motility parameters and clinical characteristics. BMC Gastroenterol 2016;16:26.

41. Mani J, Madani S. Pediatric abdominal migraine: current perspectives on a lesser known entity. Pediatric Health Med Ther 2018;9:47-58.

42. Albers L, von Kries R, Straube A, Heinen F, Obermeier V, Landgraf MN. Do pre-school episodic syndromes predict migraine in primary school children? A retrospective cohort study on health care data. Cephalalgia 2019;39:497-503.

43. Gelfand AA. Episodic syndromes that may be associated with migraine: A.K.A. 'the childhood periodic syndromes'. Headache 2015;55:13581364.

44. Symon DN, Russell G. Double blind placebo controlled trial of pizotifen syrup in the treatment of abdominal migraine. Arch Dis Child 1995;72:48-50.

45. Donnet A, Redon S. Cyclic vomiting syndrome in children. Curr Pain Headache Rep 2018;22:30.

46. Lu PL, Saps M, Chanis RA, Velasco-Benítez CA. The prevalence of functional gastrointestinal disorders in children in Panama: a schoolbased study. Acta Paediatr 2016;105:e232-e236.

47. Chogle A, Velasco-Benitez CA, Koppen IJ, Moreno JE, Ramírez Hernández CR, Saps M. A population-based study on the epidemiology of functional gastrointestinal disorders in young children. J Pediatr 2016;179:139-143, e1.

48. Zaki EA, Freilinger T, Klopstock T, et al. Two common mitochondrial DNA polymorphisms are highly associated with migraine headache and cyclic vomiting syndrome. Cephalalgia 2009;29:719-728.

49. Ellingsen DM, Garcia RG, Lee J, et al. Cyclic vomiting syndrome is characterized by altered functional brain connectivity of the insular cortex: a cross-comparison with migraine and healthy adults. Neurogastroenterol Motil 2017;29:e13004.

50. Chelimsky TC, Chelimsky GG. Autonomic abnormalities in cyclic vomiting syndrome. J Pediatr Gastroenterol Nutr 2007;44:326-330.

51. Liao KY, Chang FY, Wu LT, Wu TC. Cyclic vomiting syndrome in Taiwanese children. J Formos Med Assoc 2011;110:14-18.

52. Prakash C, Staiano A, Rothbaum RJ,Clouse RE. Similarities in cyclic vomiting syndrome across age groups. Am J Gastroenterol 2001;96:684688.

53. Kovacic K, Sood M, Venkatesan T. Cyclic vomiting syndrome in children and adults: what is new in 2018? Curr Gastroenterol Rep 2018;20:46.

54. Tarbell SE, Li BU. Health-related quality of life in children and adolescents with cyclic vomiting syndrome: a comparison with published 
data on youth with irritable bowel syndrome and organic gastrointestinal disorders. J Pediatr 2013;163:493-497.

55. Tarbell S, Li BU. Psychiatric symptoms in children and adolescents with cyclic vomiting syndrome and their parents. Headache 2008;48:259266.

56. Li BU. Managing cyclic vomiting syndrome in children: beyond the guidelines. Eur J Pediatr 2018;177:1435-1442.

57. Hikita T, Kodama H, Ogita K, Kaneko S, Nakamoto N, Mimaki M. Cyclic vomiting syndrome in infants and children: a clinical follow-up study. Pediatr Neurol 2016;57:29-33.

58. Wessel MA, Cobb JC, Jackson EB, Harris GS Jr, Detwiler AC. Paroxysmal fussing in infancy, sometimes called colic. Pediatrics 1954;14:421435.

59. Wolke D, Bilgin A, Samara M. Systematic review and meta-analysis: fussing and crying durations and prevalence of colic in infants. J Pediatr 2017;185:55-61, e4.

60. Rhoads JM, Fatheree NY, Norori J, et al. Altered fecal microflora and increased fecal calprotectin in infants with colic. J Pediatr 2009;155:823$828, \mathrm{e} 1$.

61. Leppälehto E, Pärtty A, Kalliomäki M, Löyttyniemi E, Isolauri E, Rautava S. Maternal intrapartum antibiotic administration and infantile colic: is there a connection? Neonatology 2018;114:226-229.

62. Oosterloo BC, van Elburg RM, Rutten NB, et al. Wheezing and infantile colic are associated with neonatal antibiotic treatment. Pediatr Allergy Immunol 2018;29:151-158.

63. Zeevenhooven J, Browne PD, LHoir MP, de Weerth C, Benninga MA. Infant colic: mechanisms and management. Nat Rev Gastroenterol Hepatol 2018;15:479-496.

64. Savino F, Cordisco L, Tarasco V, et al. Antagonistic effect of Lactobacillus strains against gas-producing coliforms isolated from colicky infants. BMC Microbiol 2011;11:157.

65. Pärtty A, Kalliomäki M, Salminen S, Isolauri E. Infantile colic is associated with low-grade systemic inflammation. J Pediatr Gastroenterol Nutr 2017;64:691-695.

66. Kaymaz N, Yıldırım Ş, Topaloğlu N, et al. Prenatal maternal risk factors for infantile colic. Nurs Child Young People 2015;27:32-38.

67. Canivet CA, Ostergren PO, Jakobsson IL, Dejin-Kaelsson E, Hagander BM. Infantile colic, maternal smoking and infant feeding at 5 weeks of age. Scand J Public Health 2008;36:284-291.

68. Paradise JL. Maternal and other factors in the etiology of infantile colic: report of a prospective study of 146 infants. JAMA 1966;197:191-199.

69. Alexander CP, Zhu J, Paul IM, Kjerulff KH. Fathers make a difference: positive relationships with mother and baby in relation to infant colic. Child Care Health Dev 2017;43:687-696.

70. van den Berg MP, van der Ende J, Crijnen AA, et al. Paternal depressive symptoms during pregnancy are related to excessive infant crying. Pediatrics 2009;124:e96-e103.

71. Milidou I, Søndergaard C, Jensen MS, Olsen J, Henriksen TB. Gestational age, small for gestational age, and infantile colic. Paediatr Perinat Epidemiol 2014;28:138-145.

72. Søndergaard C. Fetal growth and infantile colic. Arch Dis Child Fetal Neonatal Ed 2000;83:F44-F47.
73. Smarius LJ, Strieder TG, Loomans EM, et al. Excessive infant crying doubles the risk of mood and behavioral problems at age 5: evidence for mediation by maternal characteristics. Eur Child Adolesc Psychiatry 2017;26:293-302.

74. Savino F, Castagno E, Bretto R, Brondello C, Palumeri E, Oggero R. A prospective 10-year study on children who had severe infantile colic. Acta Paediatr Suppl 2005;94:129-132.

75. Hemmi MH, Wolke D, Schneider S. Associations between problems with crying, sleeping and/or feeding in infancy and long-term behavioural outcomes in childhood: a meta-analysis. Arch Dis Child 2011;96:622-629.

76. Levinsky Y, Eidlitz-Markus T. Comparison of the prevalence of infantile colic between pediatric migraine and other types of pediatric headache. $\mathrm{J}$ Child Neurol 2020;35:607-611.

77. Romanello S, Spiri D, Marcuzzi E, et al. Association between childhood migraine and history of infantile colic. JAMA 2013;309:1607-1612.

78. Katerji MA, Painter MJ. Infantile migraine presenting as colic. J Child Neurol 1994;9:336-337.

79. Gelfand AA, Buse DC, Cabana MD, Grimes B, Goadsby PJ, Allen IE. The association between parental migraine and infant colic: a crosssectional, web-based, U.S. survey study. Headache 2019;59:988-1001.

80. Gelfand AA, Thomas KC, Goadsby PJ. Before the headache: infant colic as an early life expression of migraine. Neurology 2012;79:13921396.

81. Hjern A, Lindblom K, Reuter A, Silfverdal SA. A systematic review of prevention and treatment of infantile colic. Acta Paediatr 2020;109:17331744.

82. Steutel NF, Zeevenhooven J, Scarpato E, et al. Prevalence of functional gastrointestinal disorders in european infants and toddlers. J Pediatr 2020;221:107-114.

83. Devanarayana NM, Rajindrajith S, Pathmeswaran A, Abegunasekara C, Gunawardena NK, Benninga MA. Epidemiology of irritable bowel syndrome in children and adolescents in Asia. J Pediatr Gastroenterol Nutr 2015;60:792-798.

84. Scarpato E, Kolacek S, Jojkic-Pavkov D, et al. Prevalence of functional gastrointestinal disorders in children and adolescents in the Mediterranean region of Europe. Clin Gastroenterol Hepatol 2018;16:870-876.

85. Elsenbruch S. Abdominal pain in irritable bowel syndrome: a review of putative psychological, neural and neuro-immune mechanisms. Brain Behav Immun 2011;25:386-394.

86. Di Lorenzo C, Youssef NN, Sigurdsson L, Scharff L, Griffiths J, Wald A. Visceral hyperalgesia in children with functional abdominal pain. J Pediatr 2001;139:838-843.

87. Hollier JM, van Tilburg MAL, Liu Y, et al. Multiple psychological factors predict abdominal pain severity in children with irritable bowel syndrome. Neurogastroenterol Motil 2019;31:e13509.

88. Hollister EB, Oezguen N, Chumpitazi BP, et al. Leveraging human microbiome features to diagnose and stratify children with irritable bowel syndrome. J Mol Diagn 2019;21:449-461.

89. Shulman RJ, Öhman L, Stridsberg M, Cain K, Simén M, Heitkemper $\mathrm{M}$. Evidence of increased fecal granins in children with irritable bowel syndrome and correlates with symptoms. Neurogastroenterol Motil 


\section{9;31:e13486.}

90. Shulman RJ, Devaraj S, Heitkemper M. Gut permeability is affected by sex and increased in children with irritable bowel syndrome but not in functional abdominal pain. Neurogastroenterol Motil 2020;32:e13765.

91. Di Nardo G, Barbara G, Cucchiara S, et al. Neuroimmune interactions at different intestinal sites are related to abdominal pain symptoms in children with IBS. Neurogastroenterol Motil 2014;26:196-204.

92. Loo EXL, Wang Y, Siah KTH. Association between irritable bowel syndrome and allergic diseases: to make a case for aeroallergen. Int Arch Allergy Immunol 2020;181:31-42.

93. Brown SC, Whelan K, Gearry RB, Day AS. Low FODMAP diet in children and adolescents with functional bowel disorder: a clinical case note review. JGH Open 2020;4:153-159.

94. Chumpitazi BP, Weidler EM, Lu DY, Tsai CM, Chulman RJ. Selfperceived food intolerances are common and associated with clinical severity in childhood irritable bowel syndrome. J Acad Nutr Diet 2016;116:1458-1464

95. van Tilburg MA, Levy RL, Walker LS, et al. Psychosocial mechanisms for the transmission of somatic symptoms from parents to children. World J Gastroenterol 2015;21:5532-5541.

96. Zeevenhooven J, Rutten JMTM, van Dijk M, Peeters B, Benninga MA. Parental factors in pediatric functional abdominal pain disorders: a cross-sectional cohort study. J Pediatr Gastroenterol Nutr 2019;68:e20e26.

97. Rahal H, Videlock EJ, Icenhour A, et al. Importance of trauma-related fear in patients with irritable bowel syndrome and early adverse life events. Neurogastroenterol Motil 2020;32:e13896.

98. Harvey PR, Theron B, Smith SCL, et al. The association between low birth weight, childhood recollections of parental response to illness, and irritable bowel syndrome: a twin study. Neurogastroenterol Motil 2020;32:e13939.

99. Scarpato E, Auricchio R, Penagini F, Campanozzi A, Zuccotti GV, Troncone R. Efficacy of the gluten free diet in the management of functional gastrointestinal disorders: a systematic review on behalf of the Italian society of paediatrics. Ital J Pediatr 2019;45:9.

100. Devanarayana NM, Rajindrajith S. Irritable bowel syndrome in children: current knowledge, challenges and opportunities. World J Gastroenterol 2018;24:2211-2235.

101. Newlove-Delgado TV, Martin AE, Abbott RA, et al. Dietary interventions for recurrent abdominal pain in childhood. Cochrane Database Syst Rev. 2017;3:CD010972.

102. Giannetti E, Maglione M, Sciorio E, Coppola V, Miele E, Staiano A. Do children just grow out of irritable bowel syndrome? J Pediatr 2017;183:122-126, e1.

103. Rawlley B, Shah D, Narang M, Pandey M. Long-term outcome of children with recurrent abdominal pain. Indian Pediatr 2020;57:465466.

104. Lau CI, Lin CC, Chen WH, Wang HC, Kao CH. Association between migraine and irritable bowel syndrome: a population-based retrospective cohort study. Eur J Neurol 2014;21:1198-1204.

105. Sperber AD, Dumitrascu D, Fukudo S, et al. The global prevalence of IBS in adults remains elusive due to the heterogeneity of studies: a rome foundation working team literature review. Gut 2017;66:1075-1082.

106. Guariso G, Meneghel A, Dalla Pozza LV, et al. Indications to upper gastrointestinal endoscopy in children with dyspepsia. J Pediatr Gastroenterol Nutr 2010;50:493-499.

107. Robin SG, Keller C, Zwiener R, et al. Prevalence of pediatric functional gastrointestinal disorders utilizing the rome IV criteria. J Pediatr 2018;195:134-139.

108. Wauters L, Talley NJ, Walker MM, Tack J, Vanuytsel T. Novel concepts in the pathophysiology and treatment of functional dyspepsia. Gut 2020;69:591-600.

109. Romano C, Valenti S, Cardile S, Benninga MA. Functional dyspepsia: an enigma in a conundrum. J Pediatr Gastroenterol Nutr 2016;63:579584.

110. Tack J, Talley NJ. Functional dyspepsia-symptoms, definitions and validity of the rome III criteria. Nat Rev Gastroenterol Hepatol 2013;10:134-141.

111. Hijaz NM, Friesen CA, Schurman JV, Pearce RE, Abdel-Rahman SM. Plasma ghrelin and liquid gastric emptying in children with functional dyspepsia consistent with post-prandial distress syndrome. Neurogastroenterol Motil 2015;27:1120-1126.

112. Yu YH, Jo Y, Jung JY, Kim BK, Seok JW. Gastric emptying in migraine: a comparison with functional dyspepsia. J Neurogastroenterol Motil 2012;18:412-418.

113. Leung MW, Wong BP, Chao NS, Chung KW, Kwon WK, Liu KK. Electrogastrography in the management of pediatric functional dyspepsia and motility disorder. J Pediatr Surg 2006;41:2069-2072.

114. Devanarayana NM, Rajindrajith S, Perera MS, Nishanthanie SW, Benninga MA. Gastric emptying and antral motility parameters in children with functional dyspepsia: association with symptom severity. J Gastroenterol Hepatol 2013;28:1161-1166.

115. Vargas-Luna FM, Huerta-Franco MR, Schurman JV, et al. Heart rate variability and gastric electrical response to a cold pressor task in youth with functional dyspepsia. Dig Dis Sci 2020;65:1074-1081.

116. Pucci E, Di Stefano M, Miceli E, Corazza GR, Sandrini G, Nappi G. Patients with headache and functional dyspepsia present meal-induced hypersensitivity of the stomach. J Headache Pain 2005;6:223-226.

117. Singh V, Singh M, Schurman JV, Friesen CA. Histopathological changes in the gastroduodenal mucosa of children with functional dyspepsia. Pathol Res Pract 2018;214:1173-1178.

118. Yeom JS, Choi MB, Seo JH, et al. Relationship between headache and mucosal mast cells in pediatric Helicobacter pylori-negative functional dyspepsia. Cephalalgia 2013;33:323-329.

119. Neilan NA, Garg UC, Schurman JV, Friesen CA. Intestinal permeability in children/adolescents with functional dyspepsia. BMC Res Notes 2014;7:275.

120. Du LJ, Chen BR, Kim JJ, Kim S, Shen JH, Dai N. Helicobacter pylori eradication therapy for functional dyspepsia: systematic review and metaanalysis. World J Gastroenterol 2016;22:3486-3495.

121. Akbari N, Hormati A, Sharifipour E, et al. Migraine, dyspepsia, and Helicobacter pylori: zeroing in on the culprit. Iran J Neurol 2019;18:1924.

122. Browne PD, Nagelkerke SCJ, van Etten-Jamaludin FS, Benninga 
MA, Tabbers MM. Pharmacological treatments for functional nausea and functional dyspepsia in children: a systematic review. Expert Rev Clin Pharmacol 2018;11:1195-1208.

123. Di Stefano M, Pucci E, Miceli E, et al. Prevalence and pathophysiology of post-prandial migraine in patients with functional dyspepsia. Cephalalgia 2019;39:1560-1568.
124. Kumagai H, Yokoyama K, Imagawa T, Yamagata T. Functional dyspepsia and irritable bowel syndrome in teenagers: internet survey. Pediatr Int 2016;58:714-720.

125. Kurth T, Holtmann G, Neufang-Hüber J, Gerken G, Diener HC. Prevalence of unexplained upper abdominal symptoms in patients with migraine. Cephalalgia 2006;26:506-510. 